\title{
Endosonografi yapılan pankreatik kitle lezyonlarının cerrahi ve ince iğne aspirasyon biyopsi verilerinin patolojik sonuçlar ile analizi: 6 yıllık deneyim
}

\section{Analysis of endosonographed pancreatic lesions with surgical and needle aspiration biopsy data by pathological results: 6 year experience}

Memduh Şahin, Mehmet Cindoruk

Gönderilme tarihi:28.02.2018

Kabul tarihi:08.08.2018

\section{Özet}

Amaç:Endoskopik ultrasonografi (EUS) pankreas lezyonlarının değerlendirilmesinde yaygın olarak kabul edilen bir tanı yöntemidir. EUS ile yapılan ince iğne aspirasyon biyopsileri pankreatik lezyonların derecelendirilmesi ve histolojik tanı almasında önemli rol oynamaktadır. Araştırmamızda EUS ile ortaya çıkan görüntülemelerin değerlendirilmesini ve patolojik sonuçlarla uyumunu incelemeyi amaçladık.

Gereç ve Yöntem: Çalışmada abdominal bilgisayarlı tomografi ile pankreasta kitle tanısı alan 101 hastanın yapılan EUS görüntülemelerinin özellikleri derlendi. Aynı zamanda bu vakalardan bazılarına eş zamanlı ince iğne aspirasyon biyopsileri uygulandı. İnce iğne biyopsisi ve cerrahi operasyon ile elde edilen patolojik tanılar çalışmamızda ek olarak derlendi.

Bulgular: EUS ile yapılan pankreatik kitle görüntülemelerinde en sık lokalizasyon pankreas baş kesimindedir $(n=46, \% 45,5)$. EUS yapılan vakalarda en sık ön tanı pankreas karsinomu idi $(n=49, \% 48,5)$. Pankreasta kitle tespit edilen hastalardan 32'sine (\%31,7) cerrahi girişim yapıldı. EUS yapılan $30(\% 29,7)$ vakaya ince iğne aspirasyon biyopsisi uygulandı. Endosonografik olarak ince iğne aspirasyon biyopsisi yapılan vakalardan 12 'sine (\%40), cerrahi uygulanan vakaların 19'una $(\% 59,4)$ pankreas karsinomu tanısı konuldu. Araştırmamızda kitlelerin lokalizasyon, boyut ve tanısal biyopsi alım yöntemlerine göre cinsiyetler arasında farklılık bulunmamıştır. Sonuç:EUS başta pankreas karsinomları olmak üzere pankreas kitle lezyon tanısında ve cerrahi kararında önemli bir yöntemdir. Bu görüntülemelerin gerek ince iğne aspirasyon biyopsileri, gerekse daha sonra cerrahi yöntemler ile desteklenmesi tanı konulmasında hayati önem taşımaktadır.

Anahtar sözcükler:Endoskopik, ultrasonografi, pankreas, ince iğne aspirasyon, cerrahi.

Şahin M, Cindoruk M. Endosonografi yapılan pankreatik kitle lezyonlarının cerrahi ve ince iğne aspirasyon biyopsi verilerinin patolojik sonuçlar ile analizi: 6 yıllık deneyim. Pam Tıp Derg 2019;12:1-6.

\begin{abstract}
Purpose: Endoscopic ultrasonography (EUS) is a widely accepted diagnostic method for the evaluation of pancreatic lesions. Fine-needle aspiration biopsies performed with EUS play an important role in the grading and the histological diagnosis of pancreatic lesions. We aimed to evaluate the imaging findings with endosonography (EUS) and try investigate the correspondence with the patients pathological results.

Material and Methods: In our study, EUS imaging of 101 patients with pancreatic mass in abdominal computed tomography was compiled. At the same time, fine needle aspiration biopsies were applied simultaneously to some of these cases. Pathologic diagnoses obtained by aspiration needle biopsy and pancreas surgery were supplemented in our study.

Results: The most common localization in pancreatic mass imaging with EUS is in the pancreatic head (46 cases, $45.5 \%$ ). The most frequent diagnosis were pancreatic carcinoma (49 cases, $48.5 \%)$. 32 patients $(31.7 \%)$ underwent surgery for pancreatic mass. Thirty needle aspiration biopsies were performed in $30(29.7 \%)$ cases after applying EUS. Pancreatic cancer was diagnosed in $12(40 \%)$ of the patients who had endosonographically fine needle aspiration biopsy and $19(59.4 \%)$ of the surgical cases. There was no difference in pancreatic localization between the patients with the preliminary diagnosis of pancreatic cancer and other preliminary pancreatic mass diagnoses. In our study, there was no difference between the genders according to localization, size and diagnostic biopsy methods.

Conclusion:EUS is an important method in diagnosing pancreatic mass lesion, especially in pancreatic carcinomas and in surgical decision. The support of fine needle aspiration biopsies and surgical methods after these images is of vital importance in the diagnosis.
\end{abstract}

Key words: Ensoscopic, ultrasonography, pancreas, fine needle aspiration, surgery.

Şahin M, Cindoruk M. Analysis of endosonographed pancreatic lesions with surgical and needle aspiration biopsy data by pathological results: 6 year experience. Pam Med J 2019;12:1-6.

Memduh Şahin, Uzm.Dr. Sağlık Bilimleri Üniversitesi Şişli Hamidiye Etfal Eğitim ve Araştırma Hastanesi Gastroenteroloji Kliniği, isTANBUL, e-posta: memduhsahin@gazi.edu.tr (orcid.org/0000-0002-9453-100X) (Sorumlu yazar)

Mehmet Cindoruk, Prof.Dr. Gazi Üniversitesi Gastroenteroloji Bilim Dalı, ANKARA, e-posta: mehmetcindoruk@hotmail.com (orcid.org/00000001-6534-9519) 


\section{Giriş}

Duktal adenokarsinom tüm pankreatik malignitelerin \%85'ini oluşturmaktadır [1]. Genel olarak pankreas baş kısmında yer alan tümörler safra yollarına bası oluşturabildiklerinden dolayı kuyruk ve gövde lezyonlarına göre daha erken dönemde ve daha küçükken tanı alırlar [2]. Pankreatik nöroendokrin tümörler, duktüler pankreatik malignitelerden radyolojik görünümleri ile ayırt edilebilecek lezyonlardır. Nöroendokrin tümörler bilgisayarlı tomografide (BT) hipervasküler lezyonlar olarak görüntü verirler. Bu tür lezyonlar çoğunlukla $2 \mathrm{~cm}$ 'den daha küçük olduklarından dolayı tanı almaları güçtür. Somatostatin sintigrafileri ve pozitron emisyon tomografi-bilgisayarlı tomografi (PET$\mathrm{CT})$ ile bu tür tümörlerin tanı alma olasılıkları daha yüksektir [3].

Endoskopik Ultrasonografi (EUS) pankreas lezyonlarının değerlendirilmesinde yaygın olarak kullanılan bir tanı yöntemi olup, bu tetkikin alansal çözünürlük olarak diğer tanısal araçlara göre üstünlüğü bulunmaktadır [4, 5]. EUS ile yapılan ince iğne aspirasyon biyopsileri (IİAB) pankreatik lezyonların derecelendirilmesi ve histolojik tanı almasında önemli rol oynamaktadır [6]. EUS ile yapılan incelemelerin pankreas adenokarsinomlarda yüksek oranda tanısal etki ve güvenlik profiline sahip olduğu ortaya konulmuştur [7]. Bunun yanında EUS incelemeleri sırasında yatak başı yapılan sitolojik örnek incelemelerinin soliter pankreatik lezyon tanısında belirgin derecede önemi olduğu düşünülmektedir [8]. Pankreatik kitle lezyonlarının tanısında EUS (\%87-\%100) incelemelerinin BT (\%53-\%86) ve manyetik rezonans görüntüleme (\%83-\%96) yöntemlerine göre daha başarılı olduğu ortaya konulmuştur [9].

Çalışmamızda EUS ile elde edilen görüntülemeleri, bu vakaların patolojik analizleri eşliğinde değerlendirmeyi ve patolojik sonuçlarla uyumunu incelemeyi amaçladık.

\section{Gereç ve yöntem}

Çalışmamız retrospektif veri analizi ve dosya tarama yöntemi ile yapıldı. Çalışma verileri 2005-2011 yılları arasında tek merkezli ve tek operatör tarafından yapılan EUS incelemeleri sonuç analizlerinden toplandı. Abdominal BT'de pankreasta kitle görünümü tespit edilen 101 hastanın EUS bulguları incelendi. Pankreatik kitle tespit edilen vakaların incelemeleri lineer 3,8 mm'lik tek çalışma kanallı Echoendoskopi (Pentax, Montwale, NJ, USA) cihazı ile yapıldı. Çevresel vasküler incelemeler için doppler ultrasonografi kullanıldı. Ayrıca dosya taramaları ile EUS eşliğinde yapılan IIAB ve cerrahi olarak patolojik sonuçları bulunan vakaların sonuçları derlendi. Tüm hastalara işlem öncesi optimal EUS uygulaması sağlanması amacı ile hafif derecede sedasyon uygulandı. İşlem başında aspire edilen preparatların sitopatolojik değerlendirmelerinde Quick MGG (Bio-Optica,Milan, Italy) malzemesi ile boyama yapıldı.

\section{İstatistiksel analiz}

Analizler için "Statistical Package for the Social Sciences17 for windows" (SPSS 17 Inc. Chicago,IL) istatistik programı kullanıldı. Araştırmada kurtiosis ve skewnes değerleri +1,5, -1,5 arasında olan değişkenler homojen olarak kabul edilmiştir. Kategorik olmayan parametrik değişkenler bağımzıs değişkenler için $T$ testi yöntemi ile değerlendirilmiştir. Kategorik değişkenler arasındaki farklılık ölçümleri için Ki-Kare testi kullanıldı. Ki-Kare analizlerinde Montanegro düzeltimi uygulandı. Analizlerde anlamlılık $p<0,05$ olarak kabul edildi.

\section{Bulgular}

Hastaların 52'si $(\% 51,5)$ erkek, 49'u $(\% 48,5)$ kadındı. EUS uygulanan hastaların ortalama yaşı $60,8 \pm 12,9$ 'di (20-87 yaş). EUS ile yapılan pankreatik kitle görüntülemelerinde en sık tespit edilen kitle lokalizasyonu pankreas baş kesiminde idi ( $n=46, \% 45,5) .56$ vakada kitle boyutları ölçülebilmiş olup ortalama kitle çapı 2,95 cm (Minimum: 0,8; maximum:8 cm) olarak hesaplanmıştır. Otuz-iki $(\% 32,7)$ vakada lokalizasyon tespit edilemedi. On-sekiz $(\% 17,8)$ vakada pankreatik soliter görünüm gövdede ve $5(\% 5)$ vakada pankreatik kuyruktaydı. EUS yapılan vakalar arasında en sık olarak hastalara pankreas karsinomu ön tanısı konuldu ( $n=49$, $\% 48,5)$. EUS görüntülemelerinde inoperatif vaka olduğu tespit edilen hastalarda biyopsi yapılmamış olup, klinik takip yapıldı ve/veya diğer tedaviler uygulandı. EUS yapılan 15 $(\% 14,9)$ vakada herhangi bir tanı konulmamış olup, $12(\% 11,9)$ vakada pankreatik kitleler benign karakterde kabul edildi (Şekil 1). 
EUS yapılan pankreatik kitle grubunda görüntülemelere göre yapılan ön tanılar Şekil 2'de belirtilmektedir. Pankreasta kitle tespit edilen hastalardan 32'sine $(\% 31,7)$ cerrahi girişim yapıldı. EUS yapılan $30(\% 29,7)$ vakaya IIIAB uygulandı. EUS ve IİAB yapılan vakalardan sadece 2'sinde $(\% 6,6)$ tanısal açıdan yeterli sonuca ulaşılamadı. EUS ve IIAB yapılan $16(\% 53,3)$ vakada malign nitelikte patolojik sonuçlara ulaşılırken, (pankreas karsinomu, nöroendokrin tümör, gastrointestinal stromal tümör vb.), 13 (\%43,4) vakada aspirasyon sonuçları benign karakterde geldi. EUS yapılan 32 (\%31,7) vakaya daha sonra cerrahi uygulandı. EUS görüntülemesinde ön tanı olarak pankreas karsinomu düşünülen hastaların 40'ında $(\% 39,6)$ patolojik, cerrahi ve diğer görüntüleme teknikleri ile yapılan değerlendirmelerde (inoperatif vakalar) tanı uyumlu bulunurken (pozitif prediktif), EUS görünümü ile pankreas karsinomu düşünülmeyen 9 pankreatik kitle vakasında ise belirtilen diğer ileri tanı yöntemleri ile pankreas karsinomu tanısı konuldu. EUS görüntülemelerinde pankreas karsinomu düşünülen vakalarla diğer tanı düşünülen vakalar karşılaştırıldığında gruplar arasında pankreasta lokalizasyon yerleri (Baş, Gövde, Kuyruk) açısından istatistiksel farklılık saptanmadı (p:0,814). Cinsiyetlere göre karşılaştırıldığında hasta yaşı, kitle boyutu, kitlr lokalizasyonu, cerrahi ve İ̈AB uygulanan vakalar arasında istatistiksel farklılık saptanmamıştır. Cinsiyetlere göre konulan tanılar, lezyon lokalizasyonları ve patolojik örnek alım yöntemleri Tablo 1'de özetlenmiştir. EUS yapılan pankreatik kitle patoloji sonuçları Tablo 2'de özetlenmiştir.

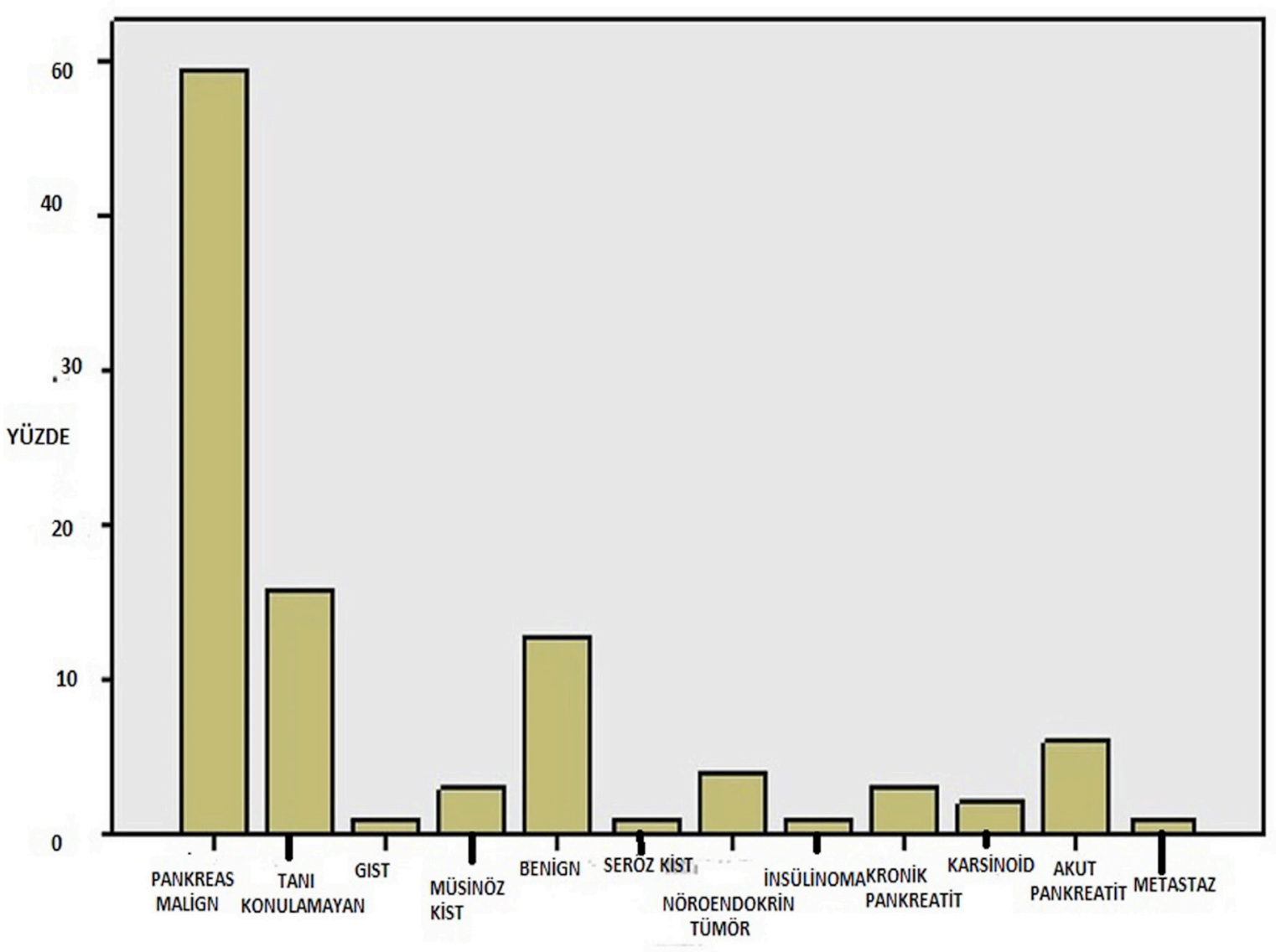

TANI

Şekil 1. Endoskopik Ultrasonografi yapılan pankreatik kitle grubunda görüntülemelere göre yapılan ön tanılar. 


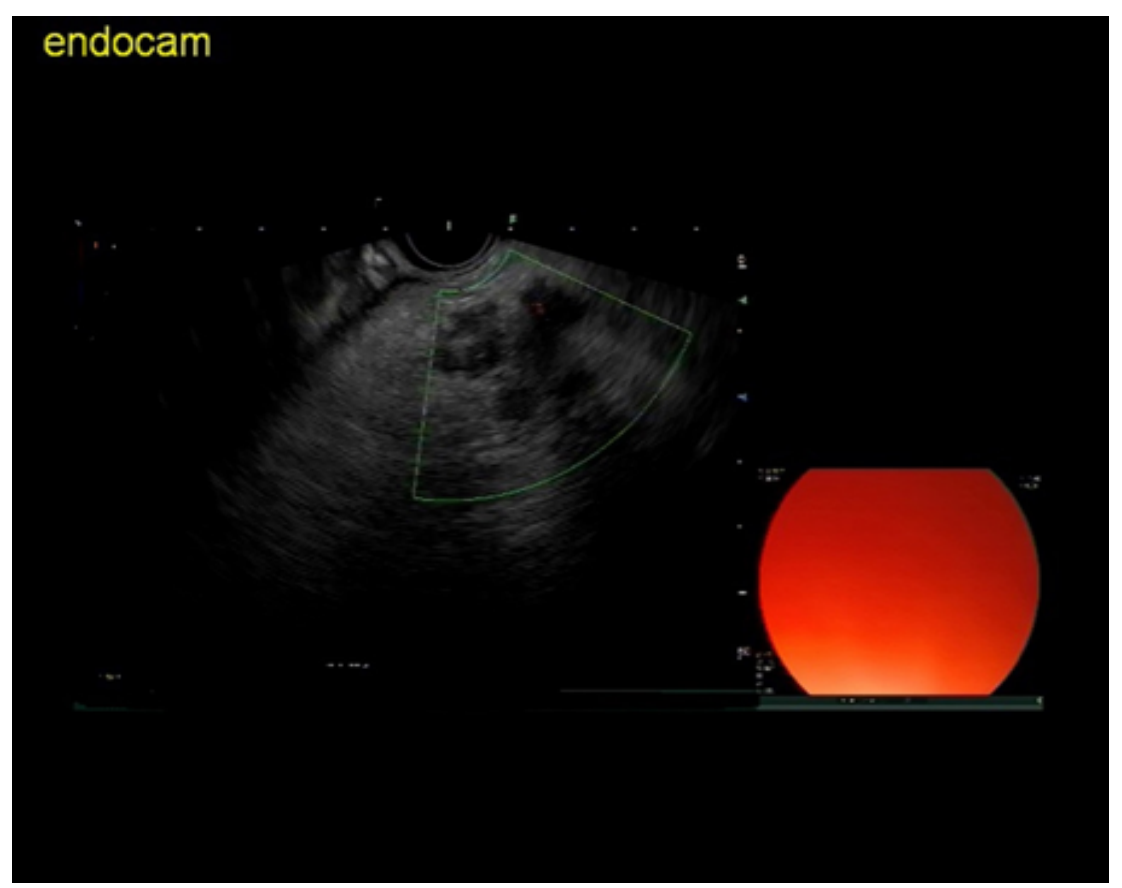

Şekil 2. EUS yapılan pankreatik kitlenin sonografik görüntüsü.

Tablo1. Cinsiyetlere göre endosonografi (EUS) uygulanan vakaların yaş, pankreas lokalizasyon, kitle boyutu, EUS-İnce iğne aspirasyon biyopsisi ve cerrahi sonuçlarının dağılımı

\begin{tabular}{llll}
\hline & $\begin{array}{l}\text { Erkek } \\
(\mathrm{n}=52)\end{array}$ & $\begin{array}{l}\text { Kadın } \\
(\mathrm{n}=49)\end{array}$ & $\mathrm{p}$ \\
\hline Yaş & $60,7 \pm 11,8$ & $60,9 \pm 14,2$ & 0,9 \\
Kitle boyutu & $2,79 \pm 1,6$ & $3,06 \pm 1,4$ & 0,5 \\
Kitle Lokalizasyonu & Baş : $24(\% 46,2)$ & Baş:22 $(\% 44,9)$ & 0,54 \\
& Gövde: $8(\% 15,4)$ & Gövde:10 $(\% 20,4)$ & \\
& Kuyruk:4 $(\% 7,7)$ & Kuyruk:1 (\%2) & \\
EUS-ïAB+ & Belirlenemeyen:16 (\%30.8) & Belirlenemeyen:16 (\%32,7) & 0,12 \\
CERRAHi + & $19(\% 36,5)$ & $11(\% 22,4)$ & 0,67 \\
\hline
\end{tabular}

EUS: Endoskopik Ultrasonografi, İ̈AB: İnce iğne aspirasyon biyopsisi.

Tablo 2. Endosonografi sonunda uygulanan ince iğne aspirasyon biyopsisi ve cerrahi biyopsi tanı sonuçları

\begin{tabular}{lll}
\hline & $\begin{array}{l}\text { EUS-iiAB } \\
(\mathrm{n}=30)\end{array}$ & $\begin{array}{l}\text { EUS-CERRAHI } \\
(\mathrm{n}=32)\end{array}$ \\
\hline Pankreas karsinomu & $12(\% 40)$ & $19(59,4)$ \\
Tanı konulamayan & $2(\% 6,7)$ & $1(3,1)$ \\
GIST & $2(\% 6,7)$ & $1(3,1)$ \\
Müsinöz kist adenom & $2(\% 6,7)$ & $1(3,1)$ \\
Benign Kitle & $8(\% 26,7)$ & $4(12,5)$ \\
Serözkistadenom & - & $1(3,1)$ \\
Nöroendokrin & $2(\% 6,7)$ & $3(\% 12,4)$ \\
Kronik pankreatit & $1(\% 3,3)$ & $1(3,1)$ \\
Akut pankreatit & $2(\% 6,7)$ & $1(\% 3,1)$ \\
Metastaz & $1(\% 3,3)$ & - \\
\hline
\end{tabular}

EUS: Endoskopik Ultrasonografi, IIIAB: Ince iğne aspirasyon biyopsisi, GiST: Gastrointestinal stromal tümör 


\section{Tartışma}

Çalışmamızda pankreasta kitlesi olan ve EUS yapılan 101 vakanın sonuçları değerlendirilmiş olup, bu hastalarda daha sonra gerek İ̈AB gerekse cerrahi yöntem ile ortaya konan patolojik veriler analiz edildi. Pankreasta kitle ön tanısı ile yapılan tüm EUS görüntülemelerinin yarısındandan fazlasında endosonografik olarak pankreas karsinomu ön tanısı konuldu ve patolojik incelemelerde bu ön tanıların yarısının histopatolojik olarak kesinleştirildiği görüldü. Vakaların yaklaşık 1/3'ünde tanı konulamayarak takip önerildi ya da tanı benign karakterde lezyonlar ile uyumlu bulundu. Çok az vakada tanılar müsinöz kist, seröz kist ya da nöroendokrin tümör ile uyumlu geldi. EUS görüntülemelerinde pankreatik kitle yerleşiminin en sık pankreas baş kesiminde yer aldığı izlendi. EUS ile yapılan ön tanılarda pankreas karsinomu düşünülen vaka grubu ile diğer tanılardan oluşan hasta grupları arasında pankreas lokalizasyonu bakımından farklılık izlenmedi (EUS görüntülemeleri en sık pankreas baş kesiminde idi.

Du ve ark'nın [10] yaptığı bir retrospektif çalışmada pankreas protokolü ile çekilen ve BT ile kitle görünümü tespit edilen ve takibinde EUS yapılan vakalarda en çok pankreas adenokarsinomu tespit edilmiştir. Bu çalışmada ikinci sıklıkta müsinöz ve daha nadir görülen tümöral tanılar konulmuştur. Aynı çalışmada BT ile EUS bulgularının birbirleri ile destekleyici görüntüleme sonuçları ortaya koyduğu belirtilmiştir. Aynı zamanda BT görüntülemelerinin lenf nodu tutulumu, vasküler tutulum ve lezyon büyüklüğü tespitinde benzer sonuçlar oluşturduğu belirtilmiştir [10]. Araştırmamız da yukarıdaki çalışma ile benzer olarak retrospektif özelliktedir ve benzer vaka sayısı içermektedir. Bizim verilerimize göre Du ve ark'nın yaptığı değerlendirmelerden daha az sayıda vakada EUS ile pankreas karsinomu ön tanısı konulmuştur. Histopatolojik olarak da daha az sayıda pankreas karsinomu tespit edilmiştir.

Lai ve ark'nın [11] yaptığı bir çalışmada pankreasta kitle bulunan vakalarda PETCT sonuçları ile EUS eşliğinde yapılan IIAB sonuçları karşılaştırılmıştır. Bu çalışmada EUS ile yapılan IİAB'nin pankreas karsinomu tespitinde PET-CT sonuçlarına göre daha sensitif ve negatif prediktif değeri olduğu ortaya konmuştur. PET-CT ve EUS eşliğinde yapılan İAB'nin kombinasyonunun, cerrahi tedavi kararı verilirken yüksek derecede etkili olduğu bu çalışmada ifade edilmiştir [11]. Pankreasta kitle nedeni ile incelenen bu vakalarda daha az sıklıkla benign lezyonlar, kronik pankreatit ve nöroendokrin tümörler tanı olarak yer almıştır [11]. Çalışmamızda EUS+IIAB ile değerlendirilen vakaların yaklaşık yarısında pankreas karsinomu tanısı konulurken, geri kalan yarısında benign kitle, pankreatit ve nöroendokrin tümör tanısı konulmuş, ancak IİAB yapılan vakaların 3 'üne tanı konulamamıştır.

Malak ve ark'nın [12] yaptığı çalışmada EUS+IIAB, endoskopik retrograd kolanjiyo pankreatografi (ERCP) ile sitolojik örnekleme ve her iki yöntemin kombinasyonu üç grup olarak karşılaştırılmıştır. Yapılan bu çalışmada EUS+IIAB ile elde edilen örneklerin ERCP örneklerine göre pozitif prediktif değer ve sensitivite açısından daha anlamlı olduğu ortaya konulmuştur. Aynı çalışmada ERCP ve EUS ile alınan sitolojik örneklerin kombinasyonunun diğer iki tekil yönteme göre daha anlamlı olabileceği ancak çalışmanın daha yüksek sayıda örneklem grubu ile tekrar edilmesi gerektiği belirtilmiştir [12]. Çalışmamızda EUS ile yapılan İAB sonuçlarımız tek bir endosonografi uzmanının retrospektif dataları çerçevesinde oluşturulmuştur. Analizlerimizde EUS+İAB ile yapılan incelemelerde yüksek oranda tanısal doğruluk saptanmasına rağmen, çalışma dizaynı itibarı ile ERCP yapılan hastalar ile ilgili veri bulunmamaktadır.

Çalışmamızın kısıtlılıklarından biri retrospektif dosya taraması tarzında analizlerin yapılmasıdır. Diğer bir kısıtlılık ise tüm hastalara EUS eşliğinde IİAB'nin yapılmamış olmasıdır. Bununla birlikte araştırmamızda, pankreas kitlelerinin EUS ile desteklenen IIAB patolojik sonuçları ülkemiz açısından değerli veriler oluşturmaktadır. Aynı zamanda çalışmamızda tüm EUS incelemeleri tek bir operatör tarafından yapılmış olup, operatörden kaynaklanan farklılıklar bulunmamaktadır.

Sonuç olarak EUS görüntülemeleri yapılan pankreasta kitle ön tanılı hasta grupları ile yapılan çalışmamızda, en sık konulan tanı pankreas kanseridir. EUS ile görüntülenen kitle lezyonlarının çoğunluğu pankreas baş kesiminde yer almaktadır. Cinsiyetlere göre pankreasta cerrahi uygulanma, kitle boyutu, İAB ve yaş 
dağılımları açısından farklılık bulunmamaktadır. Pankreatik EUS görüntülemeleri İंAB eşliğinde yapıldığında yüksek oranda bir tanısal doğruluk elde edilebilmektedir.

Çıkar İlişkisi: Yazarlar çıkar ilişkisi olmadığını beyan eder.

\section{Kaynaklar}

1. Klimstra DS. Nonductal neoplasms of the pancreas. Mod Pathol 2007;20:94-112.

2. Klimstra DS, Pitman MB, Hruban RH. An algorithmic approach to the diagnosis of pancreatic neoplasms. Arch Pathol Lab Med 2009;133:454-464.

3. Scheithauer K, Miederer M, Gaertner FC. PET-CT bei neu- roendokrinen Tumoren und nuklear medizinische Thera- piemöglichkeiten. Radiologe 2009;49:217-223.

4. Rösch T, Lorenz R, Braig C, Classen M. Endoscopic ultrasonography in diagnosis and staging of pancreatic and biliary tumors. Endoscopy 1992;24:304-308.

5. Gress FG, Hawes RH, Savides TJ, ark. Role of EUS in the preoperative staging of pancreatic cancer: a large single-center experience. Gastrointest Endosc 1999;50:786-791.

6. Lepanto L, Arzoumanian Y, Gianfelice D, et al. Helical CT with $C T$ angiography in assessing periampullary neoplasms: identification of vascular invasion. Radiology 2002;222:347-352.

7. Hewitt MJ, McPhail MJ, Possamai L, Dhar A, Vlavianos $P$, Monahan KJ. EUS-guided FNA for diagnosis of solid pancreatic neoplasms:a meta-analysis. Gastrointest Endosc 2012;75:319-331.

8. Klapman JB, Logrono R, Dye CE, Waxman I. Clinical impact of on-site cytopathology interpretation on endoscopic ultrasound-guided fine needle aspiration. Am J Gastroenterol 2003;98:1289-1294.

9. Legmann $P$, Vignaux $O$, Dousset $B$, et al. Pancreatic tumors: comparison of dual-phase helical CT and endoscopic sonography.AJR Am J Roentgenol 1998;170:1315-1322.

10. Du T, Bill KA, Ford J, et al. The diagnosis and staging of pancreatic cancer: A comparison of endoscopic ultrasound and Computed Tomography with pancreas protocol. Am J Surg 2018:472-475.

11. Lai JP, Yue $Y$, Zhang $W$, et al. Comparison of endoscopic ultrasound guided fine needle aspiration and $\mathrm{PET} / \mathrm{CT}$ in preoperative diagnosis of pancreatic adenocarcinoma. Pancreatology 2017;17:617-622.

12. Malak M, Masuda D, Ogura T, et al. Yield of endoscopic ultrasound-guided fine needle aspiration and endoscopic retrograde cholangiopancreatography for solid pancreatic neoplasms. Scand J Gastroenterol 2016;51:360-367. 